\title{
Fate of rubrospinal neurons after unilateral section of the cervical spinal cord in adult macaque monkeys: Effects of an antibody treatment neutralizing Nogo-A
}

\author{
P. Wannier-Morino ${ }^{a, 1}$, E. Schmidlin ${ }^{a, 1}$, P. Freund ${ }^{a}$, A. Belhaj-Saif ${ }^{a}$, J. Bloch $^{b}$, A. Mir $^{c}$, \\ M.E. Schwab ${ }^{d}$, E.M. Rouiller ${ }^{a}$, T. Wannier ${ }^{a, d, *}$ \\ ${ }^{a}$ Unit of Physiology and Program in Neurosciences, Department of Medicine, Faculty of Sciences, University of Fribourg, \\ Chemin du Musée 5, CH-1700 Fribourg, Switzerland \\ bepartment of Neurosurgery, Neurosurgery Clinic, University Hospital of Lausanne, Rue du Bugnon, CH-1011 Lausanne, Switzerland \\ ${ }^{\mathrm{C}}$ Neuroscience Research, Novartis Institute for BioMedical Research, CH-4002 Basel, Switzerland \\ ${ }^{\mathrm{d}}$ Brain Research Institute, University and ETH Zurich, Winterthurerstr. 190, CH-8057 Zürich, Switzerland
}

Keywords:

Red nucleus

Nogo-A

Spinal cord lesion

Primate

\begin{abstract}
The present study describes in primates the effects of a spinal cord injury on the number and size of the neurons in the magnocellular part of the red nucleus (RNm), the origin of the rubrospinal tract, and evaluates whether a neutralization of Nogo-A reduces the lesionedinduced degenerative processes observed in RNm. Two groups of monkeys were subjected to unilateral section of the spinal cord affecting the rubrospinal tract; one group was subsequently treated with an antibody neutralizing Nogo-A; the second group received a control antibody. Intact animals were also included in the study. Counting neurons stained with a monoclonal antibody recognizing non-phosphorylated epitopes on neurofilaments (SMI-32) indicated that their number in the contralesional RNm was consistently inferior to that in the ipsilesional RNm, in a proportion amounting up to $35 \%$. The lesion also induced shrinkage of the soma of the neurons detected in the contralesional RNm. Infusing an antiNogo-A antibody at the site of the lesion did not increase the proportion of SMI-32 positive rubrospinal neurons in the contralesional RNm nor prevent shrinkage.
\end{abstract}

\section{Introduction}

The effects of spinal cord injury on directly connected supraspinal structures like the magnocellular part of the red nucleus (RNm) are poorly known in primates. In the rat, after a spinal cord lesion at cervical levels, axotomized reticulospinal (RS) neurons shrink and display modification in the expression of various molecules (Egan et al., 1977; Kwon et al., 2002, 2004; Novikova et al., 2000; Tetzlaff et al., 1991). In this species, the RNm regains a normal aspect if brain derived neurotrophic factor (BDNF) is provided (Kwon et al., 2002; Liu et al., 1999; Novikova et al., 2000). Because neurotrophic substances are uptaken at synapses, the amount of neurotrophic factors accessible to a neuron relates ultimately to the number of synapses that this neuron possesses. Increasing this number may therefore contribute to protect a neuron from the degenerative processes triggered by axotomy.

\footnotetext{
* Corresponding author. Unit of Physiology, University of Fribourg, Chemin du Musée 5, CH-1700 Fribourg, Switzerland. Fax: +41 263009675. E-mail address: Thierry.Wannier@unifr.ch (T. Wannier).

Abbreviations: CS, corticospinal; BDNF, brain derived neurotrophic factor; RN, red nucleus; RNm, red nucleus pars magnocellularis; RNp, red nucleus pars parvocellularis; RS, rubrospinal; SCI, spinal cord injury
} 
In the monkey, a unilateral section of the dorsolateral funiculus at cervical levels provoked shrinkage of the axotomized corticospinal (CS) neurons and alteration of their expression of non-phosphorylated neurofilaments, but did not conduct to measurable cell death (Wannier et al., 2005). For the same lesion, the treatment with an antibody neutralizing the neurite growth inhibitor Nogo-A induced sprouting of CS axons (Freund et al., $2006,2007)$. In parallel to these morphological changes, the antiNogo-A treatment also enhanced functional recovery (Freund et al., 2006). In monkey, an interruption of the RS tract induced degenerative changes in the RNm (Padel et al., 1981). As the neutralization of Nogo-A in rodents promotes regeneration of CS and sprouting of RS fibres (Raineteau et al., 2002), this treatment could have the same effect in primate. In this case, the improved access to neurotrophic substances may lead to a reduction of the lesion induced degenerative changes in the $\mathrm{RNm}$. The present investigation aims at examining this issue by comparing the number and size of neurons in both RNm in monkeys subjected to a unilateral lesion of the cervical spinal cord and in intact monkeys. Moreover, the effects of a treatment with an antibody neutralizing Nogo-A on RNm neurons will be assessed.

\section{Results}

\subsection{Location and extent of the cervical lesion}

The RS tract is a crossed pathway that runs in the dorsolateral funiculus partially overlapping the lateral corticospinal tract and extending somewhat ventrally. As a consequence of this overlap, the CS and RS tracts cannot easily be segregated on a coronal section of the spinal cord. The extent and the location

\section{Anti-Nogo-A antibody treated monkeys}

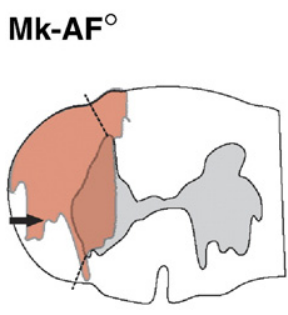

Mk-AC*

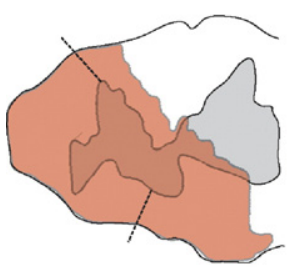

Mk-AP*

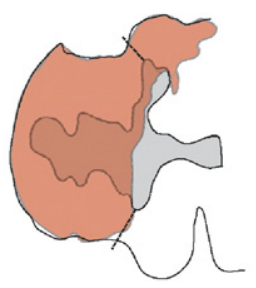

Mk-AM $^{*}$

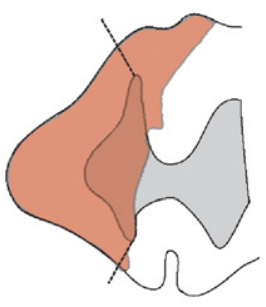

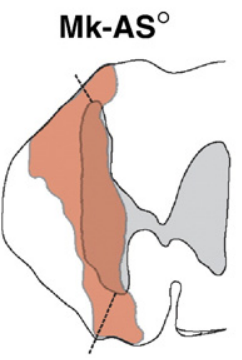

Mk-AG*

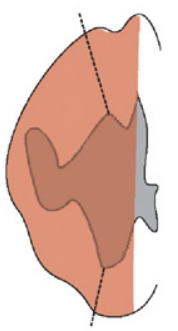

\section{Control antibody treated monkeys}
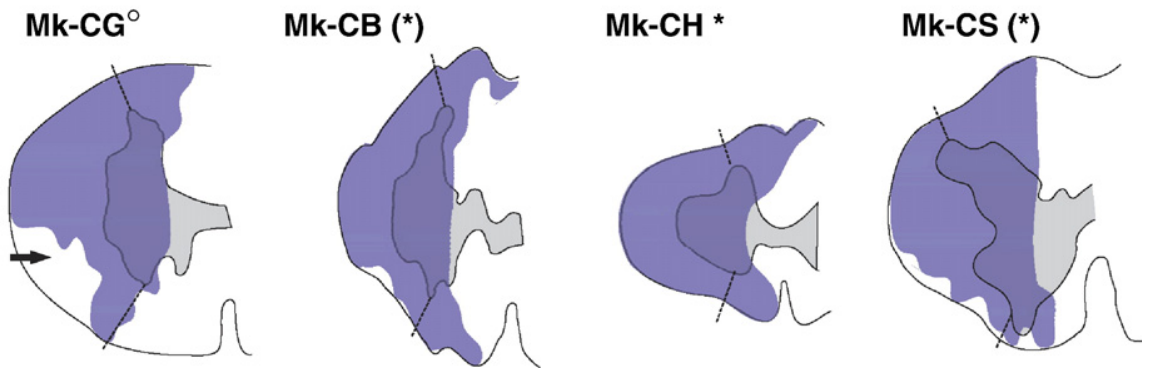

Fig. 1 - Location and extent of the cervical spinal cord lesions, performed at C7/C8 in the anti-Nogo-A antibody treated animals (six animals, red area) and in the control antibody treated animals (four animals, blue area). In one anti-Nogo-A antibody treated animal (Mk-AT) the lesion extent could not be assessed and thus it is not represented in this figure. Dashed lines indicate the extent of the lateral funiculus, going from the dorsal to the ventral rootlets. Asterisks indicate complete lesion of the zone occupied by CS/RS tracts. Asterisks in parentheses indicate a nearly complete lesion of the CS/RS tracts. Open circles indicate an incomplete lesion of the CS/RS tracts. Arrows in Mk-AF and in Mk-CG indicate the quadrant of the ventral lateral funiculus where some fibres of the RS tract might have been spared (Mk-CG) or cut (Mk-AF) by the lesion. 
Table 1 - List of cervical cord lesioned and intact monkeys included in the present study with identification code (same as in

for the lesioned animals)

\begin{tabular}{|c|c|c|c|c|c|c|c|c|c|c|c|c|c|c|c|}
\hline & & ${\mathrm{Mk}-\mathrm{AT}^{*}}$ & $\underline{\mathrm{Mk}-\mathrm{AF}}$ & $\underline{\mathrm{Mk}-\mathrm{AP}}$ & Mk-AC & Mk-AM & $\underline{\mathrm{Mk}-\mathrm{AS}}$ & Mk-CS & $\mathrm{Mk}-\mathrm{CB}$ & Mk-CG & Mk-CH & Mk-IR & $\underline{\mathrm{Mk}-\mathrm{IE}}$ & $\mathrm{Mk}-\mathrm{IZ}$ & Mk-IRh \\
\hline Species & fasc. & fasc. & mul. & fasc. & fasc. & fasc. & fasc. & mul. & fasc. & fasc. & fasc. & mul. & mul. & fasc. & mul. \\
\hline Treatment & $\begin{array}{l}\text { Anti- } \\
\text { Nogo-A } \\
\text { (hNogo) }\end{array}$ & $\begin{array}{l}\text { Anti- } \\
\text { Nogo-A } \\
\text { (hNogo) }\end{array}$ & $\begin{array}{l}\text { Anti- } \\
\text { Nogo-A } \\
(11 \mathrm{C} 7)\end{array}$ & $\begin{array}{l}\text { Anti- } \\
\text { Nogo-A } \\
(11 \mathrm{C} 7)\end{array}$ & $\begin{array}{l}\text { Anti- } \\
\text { Nogo-A } \\
\text { (hNogo) }\end{array}$ & $\begin{array}{l}\text { Anti- } \\
\text { Nogo-A } \\
\text { (hNogo) }\end{array}$ & $\begin{array}{l}\text { Anti- } \\
\text { Nogo-A } \\
(11 \mathrm{C} 7)\end{array}$ & Contr. & Contr. & Contr. & Contr. & Intact & Intact & Intact & Intact \\
\hline $\begin{array}{l}\text { Proportion of } \\
\text { hemi-section } \\
\text { extent (\%) }\end{array}$ & 78 & - & 56 & 58 & 85 & 80 & 41 & 63 & 75 & 51 & 90 & 0 & 0 & 0 & 0 \\
\hline $\begin{array}{l}\text { Lateral funiculus } \\
\text { lesion extent (\%) }\end{array}$ & 100 & - & 73.4 & 100 & 100 & 100 & 48.2 & 87 & 93.4 & 70 & 100 & 0 & 0 & 0 & 0 \\
\hline $\begin{array}{l}\text { Functional } \\
\text { Recovery (\%) }\end{array}$ & 100 & (100) & 57 & 99 & 100 & 96 & 100 & 22 & 78 & 90 & 53 & - & - & - & - \\
\hline $\begin{array}{l}\text { Completeness of } \\
\text { CS/RS section }\end{array}$ & Yes & - & No & Yes & Yes & Yes & No & Yes & Yes & No & Yes & - & - & - & - \\
\hline $\begin{array}{l}\text { Survival time } \\
\text { after lesion (days) }\end{array}$ & 112 & 97 & 144 & 160 & 135 & 138 & 282 & 198 & 225 & 140 & 138 & - & - & - & - \\
\hline $\begin{array}{l}\text { Age at sacrifice } \\
\text { (years) }\end{array}$ & 3.5 & 3.75 & 6.25 & 6.5 & $\sim 4$ & $\sim 4$ & 6.25 & 4.5 & 5 & $\sim 4$ & $\sim 4$ & 5 & $\sim 5$ & 7.75 & 6.5 \\
\hline
\end{tabular}

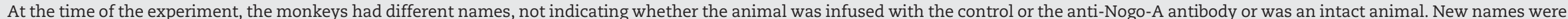
assigned to the monkeys during the writing of the manuscript to improve its readability, in consistency with Freund et al. (2006).

Under species, "mul." is for macaca mulatta while "fasc." is for macaca fascicularis.

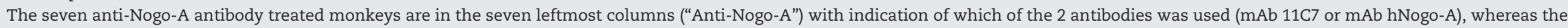
four control antibody treated monkeys ("Contr.") are in the next four columns. The four intact monkeys are in the four rightmost columns.

Proportion of hemi-section extent was calculated as the percentage of corresponding hemicord affected by the lesion on the frontal reconstruction of the cervical cord.

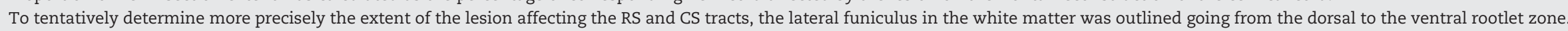
This was indicated as lateral funiculus lesion extent.

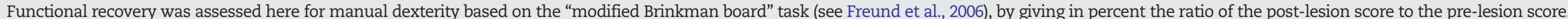
In the row "Completeness of RS section", "No" and "Yes" indicate whether the RS transection was considered as partial or as complete, respectively (for further explanation see text).

Survival time: number of days separating the cervical cord lesion and the sacrifice of the animal.

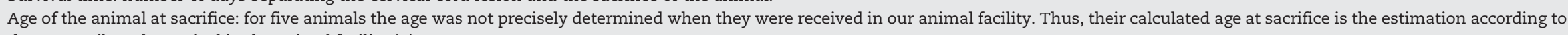
the age attributed at arrival in the animal facility $(\sim)$.

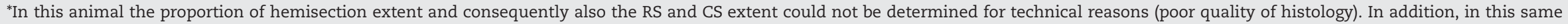
animal the lesion was too caudal and thus the $100 \%$ functional recovery cannot be interpreted. 
of the cervical cord hemi-section are shown in Fig. 1 for 10 of the 11 lesioned monkeys. The total extent of the lesion is given in Table 1 (percentage of hemi-section). To tentatively determine more specifically the extent of the lesion affecting the territory comprising the RS and CS tracts we considered only the lateral funiculus, i.e. the white matter going from the dorsal to the ventral rootlet zone (dashed lines in Fig. 1). A lesion extent was thus recalculated reflecting more accurately
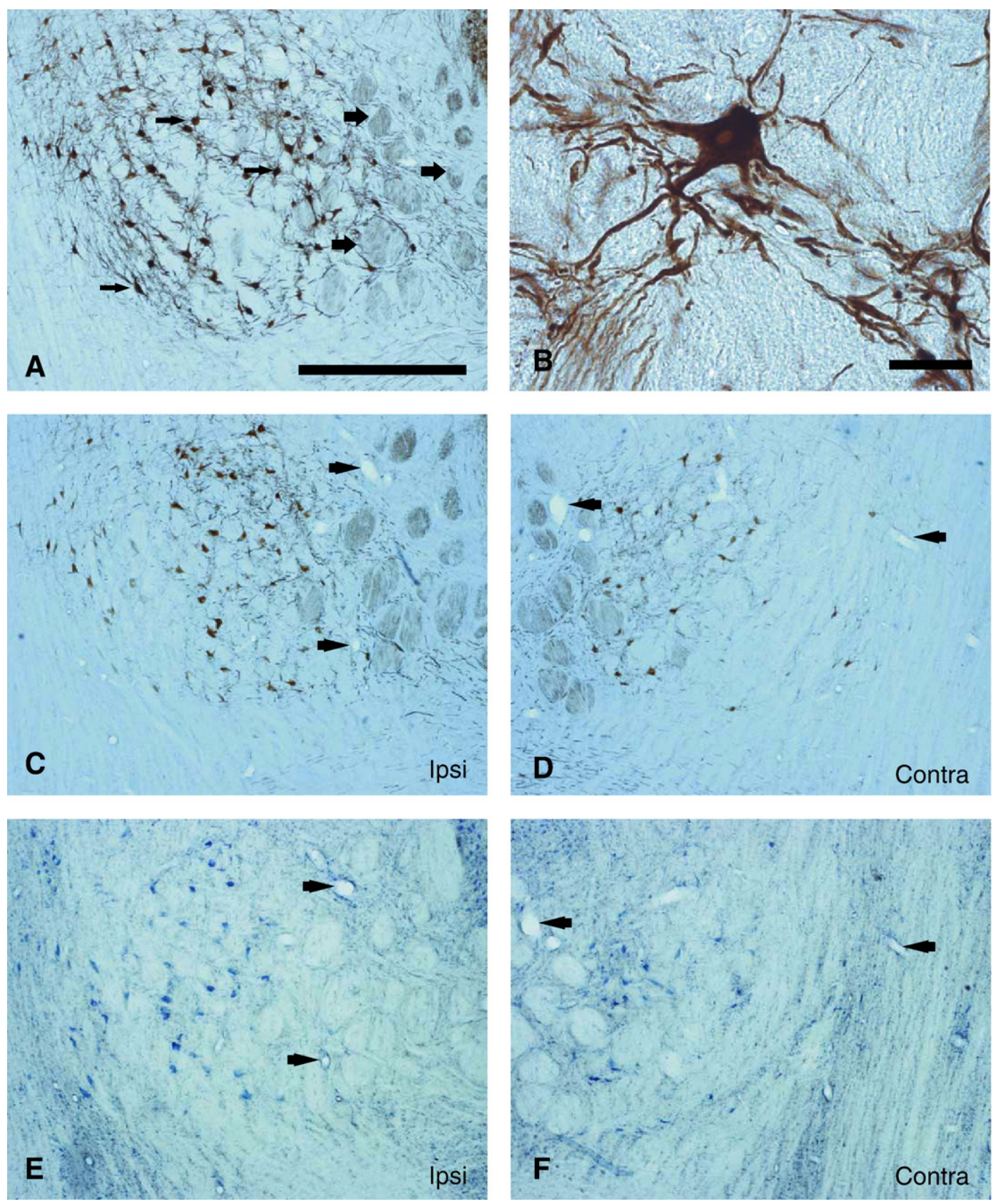

Fig. 2 - A-D: Photomicrographs of SMI-32 stained frontal sections of the RNm. In panel A the RNm of an intact animal (Mk-IR) is shown. Note the proximity of the RNm with the roots of the oculomotor nerve (large arrows). Large and darkly positive SMI-32 neurons (thin arrows point to a few of them) are loosely packed and are arranged to form a round shaped nucleus. At higher magnification (panel B), neurons show a multipolar shape with several dendritic processes. The neuron in the image has a clearly visible nucleus, which was the criterion to be included in the morphometric analysis (cell count and somatic size). Panels C and D show the RNm on the ipsi- and contralesional side respectively of a representative animal subjected to a unilateral spinal cord lesion (Mk-CS). Both sides appear less intensively stained if compared to panel A, reflecting individual and methodological variability. In panel $\mathrm{D}$ (contralesional $\mathrm{RNm}$ ) the number of SMI-32 positive cells appears lower than in panel C (ipsilesional RNm). In addition, the intensity of staining appears also reduced in panel D as compared to panel C and A. E-F: Photomicrographs of Nissl stained sections of the RNm adjacent to sections displayed in C and D, respectively. Arrows in $C$ and $E$ and in $D$ and $F$ respectively indicate the same blood vessels. Similarly to SMI-32 staining, the number of cell bodies appears lower in panel $F$ than in panel E. Scale bar in A (same for C, D, E, F): 1 mm. Scale bar in B: $100 \mu \mathrm{m}$. 


\section{Table 2 - Summary of differences in cell number and somatic size in RNm on each side in the monkeys included in the present study}

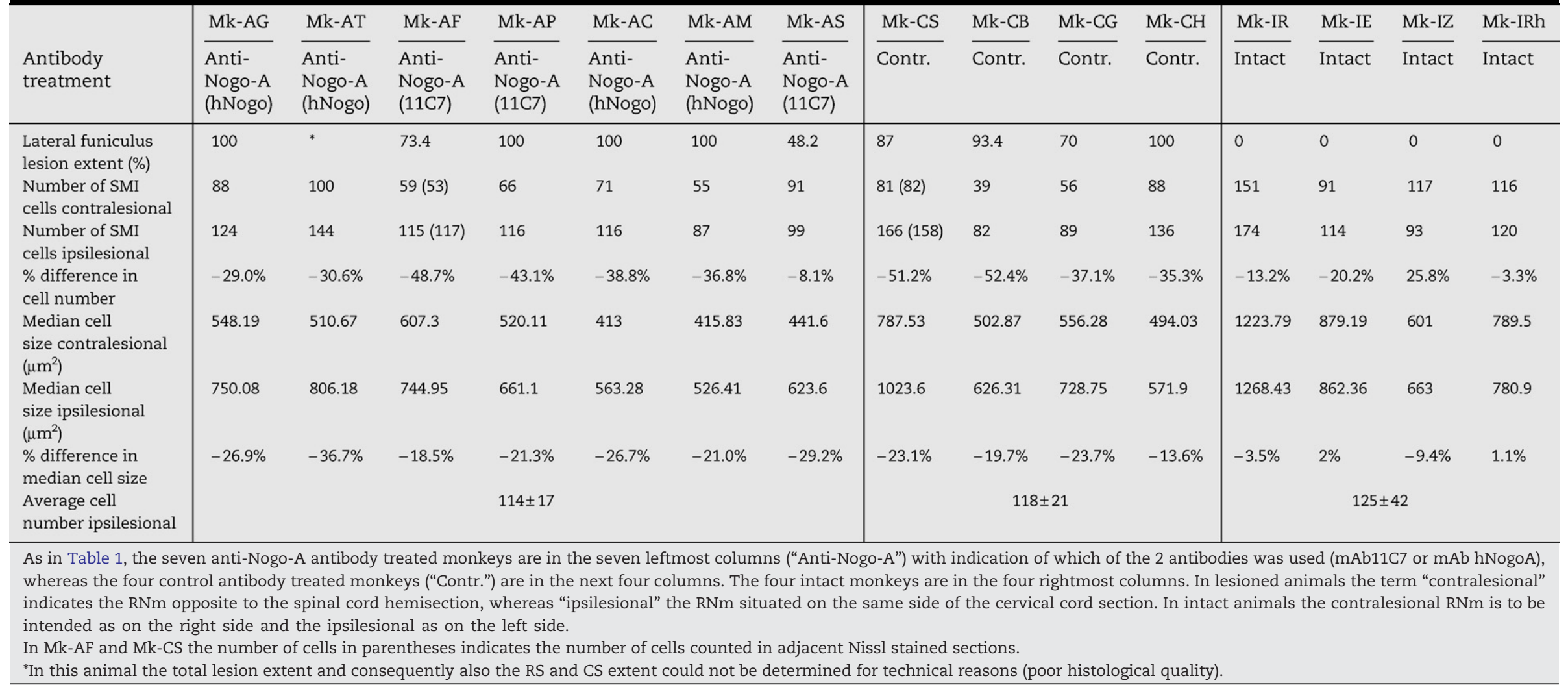


the portion of CS and RS tracts affected by the lesion (Table 1: lateral funiculus lesion extent in \%). In five of the 11 lesioned monkeys, the section of the lateral funiculus between the dorsal and the ventral rootlets reached $100 \%$ of the territory and thus the lesion of the RS tract was considered as complete in these animals (asterisks in Fig. 1). In two animals (Mk-CS and $\mathrm{Mk}-\mathrm{CB}$ ), the lesion covered more than $87 \%$ of the lateral funiculus and the territory spared by the lesion was situated most laterally (Fig. 1), a territory normally not occupied by the RS tract. These two monkeys were thus considered as subjected to nearly complete transection of the RS tract (asterisk in parentheses in Fig. 1). In contrast, in three monkeys, the lesion extent in the lateral funiculus was below 75\% (open circles in Fig. 1), and therefore the lesion of the RS tract was considered incomplete. Particularly, in Mk-AS the extent of the lesioned lateral funiculus was below $50 \%$.

\subsection{The number of SMI-32 positive neurons in the contralesional $\mathrm{RNm}$ is reduced in lesioned animals}

The RNm is located in the ventral part of the midbrain. On coronal sections stained for SMI-32, RNm was easily identified by its large and strongly stained neurons, its ovoid shape and its vicinity to the roots of the oculomotor nerve (Fig. 2A). The $\mathrm{RNm}$ was clearly distinguished from the parvocellular part of the $\mathrm{RN}(\mathrm{RNp})$ which was situated more rostrally, containing smaller, more densely packed and more faintly SMI-32 stained cells (not shown). On Nissl-stained sections adjacent to the SMI-32 labelled ones, large neurons were also visible at low magnification and their number and distribution appeared comparable to the SMI-32 pattern of distribution (Figs. 2E-F). This observation was confirmed quantitatively in two monkeys (Mk-AF and Mk-CS) by counting the cell nuclei in adjacent sections of the RNm stained respectively for SMI-32 and Nissl (numbers between parentheses in Table 2). For the other animals, as the contour of SMI-32 stained neurons was easier to define than that of Nissl stained cells, we conducted our analysis on SMI-32 stained sections. At first sight, in animals subjected to the cervical lesion, the contralesional RNm exhibited a reduction of the number of SMI-32 positive neurons as compared to the ipsilesional side (Figs. 2C-D); neurons might have degenerated or shrunken and/or reduced their expression of non-phosphorylated neurofilaments, thus loosing their strong SMI-32 staining (Wannier et al., 2005). Indeed, faintly stained RNm neurons were visible on the contralesional side at high magnification (400x). RNm neurons were counted on both sides and their somatic cross-sectional area was measured on sections spaced $400 \mu \mathrm{m}$ apart along the entire rostro-caudal extent of the RNm, only considering SMI32 labelled cell bodies with a visible nucleus (Fig. 2B). As the number of sections labelled with SMI-32 antibody and including the RNm was relatively low for each animal (6 to 9), the number of cells counted in each RNm was fairly small (Fig 3A), ranging from 39 neurons (Mk-CB contra) to 174 neurons (Mk-IR right). Indeed, the estimated number of neurons was variable across animals irrespective of the lesion and/or treatment with anti-Nogo-A or control antibodies (Table 2). This variability was best reflected by the RNm cell numbers on each side in the four intact animals (Table 2, rightmost four columns), in which a relative difference in cell number between the two
RNm reached up to $25.8 \%$ (Fig. 3A), though not statistically significant. In the 11 monkeys subjected to the cervical lesion, there was a systematic lower number of RNm neurons contralesionally. In three monkeys the difference was statistically significant (Fig. 3A, $p<0.05$ ) whereas the difference did not reach significance level in seven monkeys $(0.05<p \leq 0.1)$. The least significant difference was found in the monkey (Mk-CG) subjected to an incomplete transection of the RS tract (Fig. 1, open circle). In Mk-AS the difference could not be statistically evaluated (see Experimental procedures). To assess further the impact of the lesion, the cell number difference was expressed in percentage between the RNm on both sides for each animal (Fig. 3B and Table 2). For animals with complete or nearly complete lesion of the RS/CS tracts territory (asterisks in Fig. 1), the percentage difference of SMI-32 positive RNm neurons between the two sides ranged from $-29.0 \%$ to $-52.4 \%$ (Figs. 3B and $\mathrm{C}$ ). In contrast, intact monkeys showed a cell number difference between the two $\mathrm{RNm}$, ranging from $-3.3 \%$ to $25.8 \%$, figures which could be considered as indicative of the interindividual and intrinsic methodological variability. Interestingly, Mk-AF, which had a relatively restricted lesion extent (73.4\%), exhibited a high cell number difference between the two RNm (-48.7\%). On the other hand Mk-CG, which had also an incomplete lesion comparable to $\mathrm{Mk}-\mathrm{AF}$, showed a relatively lower cell number difference ( $-37.1 \%$, not significant, see above), although still higher than the values found in intact monkeys. In these two latter monkeys the extent of the lesion in percentage was similar; however when the territory of the lateral funiculus lesioned was considered it appeared that in Mk-AF the part of the lesion going ventro-laterally was coherent with a bigger impact on the RS tract than in Mk-CG (arrows in Fig. 1). Finally in Mk-AS, which had a highly incomplete lesion (below 50\%) sparing a large part of the territory occupied by the RS tract (Fig. 1), the cell number difference was accordingly comparable to values observed in intact animals.

In the lesioned monkeys, no obvious relationship was found between these values of RNm neurons and the fact that some animals were treated with an anti-Nogo-A antibody whereas other animals received a control antibody (Fig. 3C). To statistically evaluate this observation, we compared the values of cell number difference between the RNm on the two sides expressed in percentage among the three groups of animals (Group 1, red in Fig. 3B: lesioned, anti-Nogo-A antibody treated animals; Group 2, blue: lesioned, control antibody treated animals; Group 3, green: intact animals) using the non-parametric Mann and Whitney test. The comparison values between groups 1 and 2 were not statistically significant $(p>0.05)$, confirming thus the observation that the anti-Nogo-A antibody treatment did not prevent a reduction of the number of large SMI-32 positive RNm neurons contralesionally. On the other hand, as compared to intact animals (group 3), the difference in large SMI32 positive cell number between the two RNm was statistically significant $(p<0.05)$ in the two groups of lesioned monkeys (Fig. 3B).

\subsection{Do the SMI-32 positive RNm neurons shrink?}

As mentioned above, shrinkage of RNm neurons as consequence of the cervical hemisection has also to be considered. To address this issue, we calculated the somatic cross-sectional 
area of the RNm neurons that were included in the cell counting (Table 2), and these measurements were shown for each monkey as paired box and whisker-plots for the contralesional and ipsilesional sides, respectively (Figs. 4A-C). Figs. 4A and B show the distribution of somatic cross-sectional areas of $\mathrm{RNm}$ neurons in the anti-Nogo-A antibody treated and control anti- body treated groups for the lesioned monkeys, respectively. In all lesioned monkeys, a systematic and substantial decrease of the cross-sectional somatic area was observed in the contralesional RNm as compared to the ipsilesional RNm. For all lesioned animals, the shrinkage of cross-sectional somatic area of RNm neurons contralesionally was statistically
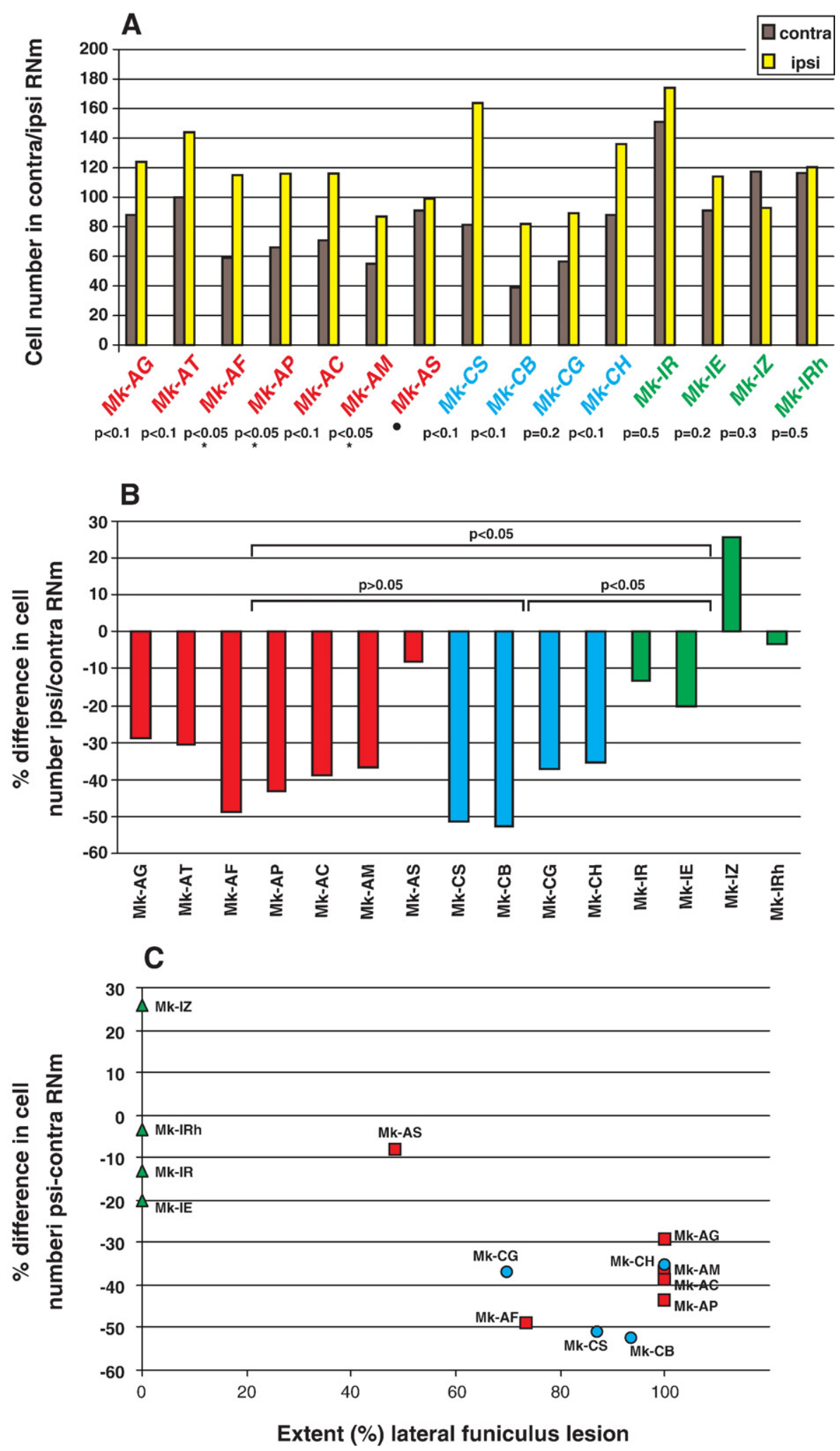
significant (Mann-Whitney U-test, $p<0.05)$, irrespective of the treatment with the anti-Nogo-A or with a control antibody. The intact animals, in sharp contrast and as expected, did not show any systematic and significant difference $(p>0.05)$ in neuronal cross-sectional somatic area between left and right $\mathrm{RNm}$ (Fig. 4C).

The percentage difference between the median values of the cross-sectional somatic areas on each RNm for each animal was calculated and the values plotted against the extent of the lateral funiculus lesion (Fig. 4D). In intact animals, the difference of the median area between the two RNm ranged from $1.1 \%$ to $-9.4 \%$. Once more these figures reflect the normal individual and methodological variability. In contrast, all animals subjected to a cervical cord hemisection exhibited a significant shrinkage of the RNm neurons contralesionally, with a difference between the two sides ranging from $-13.6 \%$ to $-36.7 \%$, not overlapping with the range found for intact monkeys (Fig. 4D).

\section{Discussion}

In the present investigation we have shown that unilateral cervical cord injury interrupting RS axons also affects the neurons of origin in the contralesional RNm. Although the majority of RS neurons in the contralesional RNm clearly survived to axotomy, there was a significant reduction of the number of SMI-32 positive neurons. In addition, these neurons showed a significant shrinkage of their soma. Finally, our results indicate that treatment with an antiNogo-A antibody, applied at the level of the spinal cord lesion, did not reduce the decrease of the number of SMI-32 positive neurons counted in the contralesional RNm or their soma shrinkage.

\subsection{Lesion extent}

In primates both the lateral CS and the RS tracts are found in the lateral funiculus of the spinal cord and influence mostly the distal but also the proximal muscles of the forelimb (Belhaj-Saif and Cheney, 2000; Belhaj-Saïf et al., 1998). In particular, though in primates the RS tract is reduced in size with respect to other mammals such as cats or rats, it has been shown that after unilateral lesion of the CS tract at the level of the pyramids, the RNm shows a certain degree of functional reorganization that may contribute to the recovery of motor function for the forelimb (Belhaj-Saïf and Cheney, 2000). However, a lesion of the lateral funiculus at cervical level of the spinal cord will affect both the RS and the CS tracts as in this area the two pathways overlap to some extent, although the RS tract lays slightly more ventrally that the CS tract in the lateral funiculus. Despite the fact that, in the present study, the RS tract was not traced, the analysis of the reconstructed cervical cord hemisections (Fig. 1) allowed assessment of the degree of completeness of RS tract transection, by expressing the lesion extent as the percentage of the quadrant of white matter going from the dorsal to the ventral rootlet zone. Tracing studies in monkeys have shown that the RS tract is included entirely in this quadrant (Burman et al., 2000b; Holstege et al., 1988).

\subsection{Cell bodies selection and analysis: technical considerations}

In the monkey the RNm constitutes the caudal third of the entire $\mathrm{RN}$ and it is composed of loosely scattered large cells together with a few smaller cells (Ralston and Milroy, 1989). In individual histological sections large neurons were few and were segregated in small groups among the fibres fascicles of the oculomotor nerve (Fig. 2A). SMI-32 labelled neurons were

Fig. 3 - A: Histograms of the number of SMI-32 positive cells (with a visible nucleus) counted in the RNm on the contralesional (brown) and ipsilesional (yellow) sides. The first seven animals (red names) were subjected to unilateral cervical cord lesion and subsequently treated with the anti-Nogo-A antibody. The next four animals (blue names) were lesioned and treated with a control antibody. The last four animals (green names) were intact. In these latter animals "contra" and "ipsi" corresponded to the left and right RNm, respectively. The statistical significance of the cell number difference between the RNm on the two sides was calculated using the Wilcoxon signed-rank, 1-tailed test. The number of neurons for each histological section of the RNm of both sides throughout the entire extent of the RNm was compared. In three of the lesioned animals this difference was statistically significant ( $p<0.05$, asterisks). In seven lesioned monkeys the difference was not statistically significant ( $p<0.1$ or $p=0.2$ in Mk-CG). All the intact animals exhibited a cell number difference that was not statistically significant. For Mk-AS the statistical significance could not be calculated (see Experimental procedures). B: Difference in the number of SMI-32 positive cells calculated in percentage between the two sides of the RNm in the animals shown in the same order as in panel A. Colour codes indicate the different animal groups as in panel A: in red the lesioned animals, treated with the anti-Nogo-A antibody; in blue the lesioned animals treated with a control antibody; in green the intact animals. In Mk-AS, characterized by an incomplete lesion of the RS tract (less than 50\%), the difference appeared comparable to the one of the intact monkeys ("green" animals). Beside this animal, the percentage difference in lesioned animals showed a high variability ranging from $17 \%$ to $35 \%$. Note that Mk-CG and Mk-AF have also an incomplete lesion of the RS tract (less than 75\%, open circles in Fig. 1). To statistically evaluate the impact of the anti-Nogo-A or control antibody treatment on the cell number difference between the RNm of the two sides, we compared the values among the three groups of animals. The difference among the two groups of lesioned animals was not statistically significant $(p>0.05)$ whereas the difference between each group of lesioned animals and the group of intact animals was statistically significant $(p<0.05)$. C: The data shown in panel B were plotted against the extent of the lesion of the lateral funiculus calculated in percentage (see Table 2). Red squares are for lesioned animals treated with the anti-Nogo-A antibody. Blue circles are for lesioned animals treated with a control antibody. Green triangles are for intact animals. The variability of the values calculated for the lesioned animals appears independent of the fact that the animal was treated with an anti-Nogo-A or a control antibody. Mk-AT is not shown as the lesion extent could not be estimated (see Table 1 and Experimental procedures). 

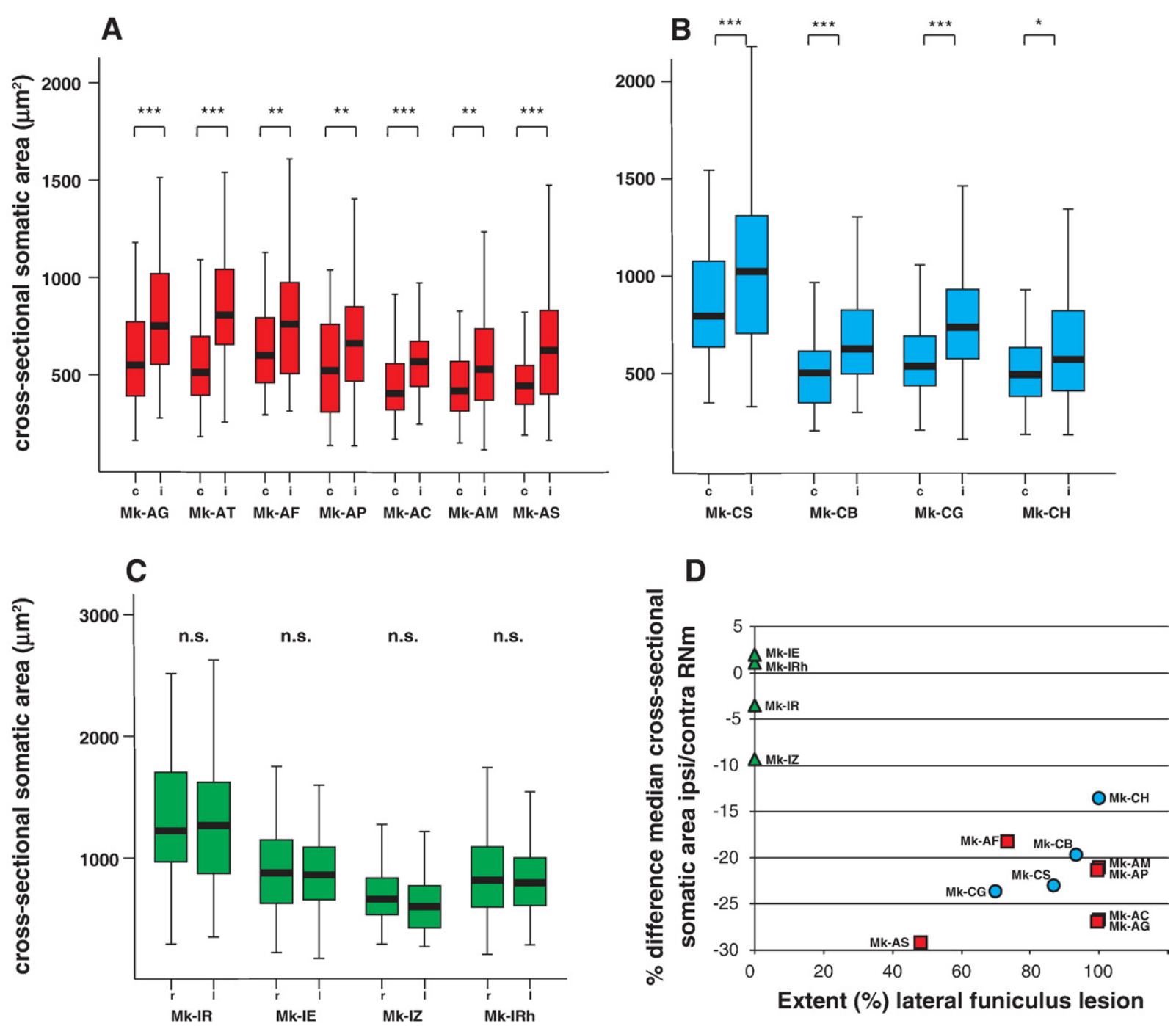

Fig. 4 - A: Box and whisker plots showing the distribution of somatic cross-sectional areas of SMI-32 positive RNm neurons in lesioned animals treated with an anti-Nogo-A antibody. For each animal the contralesional (c) and the ipsilesional (i) RNm are shown. The soma areas did not follow a normal distribution and therefore were graphically represented in the form of box and whisker plots, emphasizing the median value. Consequently, the statistical analysis was conducted using a non-parametric unpaired test (see below). In the box and whisker plots, the horizontal black line in the box corresponds to the median value, whereas the top and bottom of the box are for the 75 and 25 percentile values respectively. The top and bottom extremities of the vertical lines on each side of the box are for the 90 and 10 percentile values, respectively. A statistical comparison between the two RNm on each side was conducted for each animal using the non-parametric Mann and Whitney test. All animals of this group exhibited a statistically significant difference of soma area across the two RNm of each side $\left(^{* *}=p<0.001 ;{ }^{* * *}=p<0.0001\right)$. B: Box and whisker plots showing the distribution of somatic cross-sectional areas of SMI-32 positive neurons in lesioned animals treated with a control antibody. For each animal the contralesional (c) and the ipsilesional (i) RNm are shown. Other conventions are as in panel A. All animals of this group showed a statistically significant difference of soma area across the two RNm on each side $\left({ }^{*}=p<0.01 ;{ }^{* * *}=p<0.0001\right)$. C: Box and whisker plots showing the distribution of somatic cross-sectional areas of SMI-32 positive neurons in intact animals. The two RNm are indicated here as right ( $\mathrm{r}$ ) and left (l). As expected, the comparisons of cross sectional areas between the RNm on each side did not show any statistically significant difference (n.s. $=p>0.05$ ). D: The difference, expressed in percentage, between the median values of somatic cross-sectional areas of SMI-32 positive neurons in the contralesional and ipsilesional RNm was plotted against the extent of the lateral funiculus lesion expressed in percentage (see Table 2). Red squares are for lesioned animals treated with the anti-Nogo-A antibody. Blue circles are for lesioned animals treated with a control antibody. Green triangles are for intact animals. The variability among values in lesioned animals appears independent of the antibody treatment. Mk-AS which had a rather incomplete lesion (less than $\mathbf{5 0} \%$ ) shows a very high (the highest) value of cell surface difference between the two RNm. $\mathrm{Mk}-\mathrm{CH}$ characterized by a complete lesion has a rather low (but significant, see box plot in B) value of cell surface difference. 
rather large (Fig. 2B) and showed a radial spread of relatively large dendrites. This morphology corresponded to the description of monkey RS neurons previously reported (Burman et al., 2000a; Padel et al., 1981).

The number of SMI-32 positive neurons was estimated in one series of sections over the whole extent of the RNm. Thus, we did not count the absolute number of SMI-32 positive neurons in the $\mathrm{RNm}$. Instead, we compared the relative number of $\mathrm{RNm}$ cells counted on both sides of the brain of each animal. Because the number of SMI-32 stained neurons in RNm is relatively low (see Results), we did not use a stereological probe to estimate their number but we counted all visible nuclei of the labelled cells on the analyzed sections. This approach is considered as adequate as all samples were analyzed using the same procedure and the number of cells is low (Benes and Lange, 2001; Geuna, 2000; Lavenex et al., 2000). In the present case, in addition, the validity of the method is supported a posteriori by the absence of overlap between lesioned and intact monkeys in a large group of animals as well as by the absence of difference between the RNm on both sides in intact monkeys.

Cervical cord (C3) hemisection in rat induced, beside other molecular changes, a reduction of neurofilament mRNA in RS neurons (Tetzlaff et al., 1991). This is probably also the case in RS neurons in monkey as the labelling on the contralesional side was fainter than on the ipsilesional side. Thus it might be possible that the SMI-32 antibody would not label some neurons because the expression of the epitope recognized is strongly reduced. However, when we compared Nissl labelled sections of the RNm of lesioned animals to adjacent sections labelled with SMI-32, the numbers of cells found in RNm were comparable (Table 2).

\subsection{Cell number}

Counts of RNm cells on both sides showed inter-individual and methodological variability, as shown for intact monkeys (Figs. 3A, $B$ "green" group) where the percentage difference between the two sides ranged from $-3.3 \%$ to $25.8 \%$ but it was not statistically significant. In lesioned monkeys the difference in the number of SMI-32 positive cells detected in the contralesional and ipsilesional sides was statistically significant in three monkeys (Fig. 3A, $p<0.05$, asterisk). In the other monkeys the difference was not significant $(p>0.05)$, but as the statistical analysis was done on a relatively small number of data points (cells counted in each section, especially in Mk-CB and Mk-CG), these values indicate a tendency towards a difference in cell number between the two $\mathrm{RNm}$. In these 11 animals, the values of percentage cell difference were rather variable, ranging from $-8.1 \%$ to $-52.4 \%$. Interestingly, the two animals having the highest values (Mk-CS, $-51.2 \%$ and $\mathrm{Mk}-\mathrm{CB},-52.4 \%$ ) were also the ones having a longer period of survival after the lesion (around 200 days, Table 1). Otherwise, the high variability could not be systematically correlated to any other parameter.

In the absence of direct evidence of cell death or apoptosis, the question arises as to whether the decrease in the number of SMI-32 positive RNm neurons reported in the present study reflects cell death or rather changes in the phenotype of axotomized RS neurons which then impairs their detection. In the adult rat, some reports have suggested that SCI leads to the death of a sizable proportion of RS neurons (Houle and Ye,
1999; Mori et al., 1997; Novikova et al., 2000), while some other reports have brought evidence that the axotomized RS shrink but survive in an atrophic state (Kwon et al., 2002; Prendergast and Stelzner, 1976). These discrepancies of interpretation may result from methodological differences; in particular they may reflect the inherent difficulty to detect shrunken neurons. In the case of the monkey, chromatolytic RNm neurons have been observed after SCI, a feature that is consistent with cell death (Bodian, 1946; Padel et al., 1981). Moreover, in investigations of the fate of CS neurons using the same material as in the present report, we observed that CS neurons can be detected on SMI-32 stained material despite their axotomy induced atrophy and phenotype changes (Beaud et al., 2006; Wannier et al., 2005). These observations suggest that the method was adequate to reveal atrophic neurons and hence that in the primate, some RS neurons die in consequence of an axotomy at the level of the cervical spinal cord. This would in turn indicate that RS neurons in different species react differently to axotomy. In the adult opossum, most RS neurons survive SCI, but a limited proportion of RS neurons consistently disappears, an observation that was interpreted as indicative of limited cell death (Xu and Martin, 1990). Furthermore, this idea is supported by observations on CS neurons. In the adult rat, SCI leads to apoptosis in MI (Hains et al., 2003; Lee et al., 2004). However, as mentioned above, in the macaque, the total number of SMI-32 positive cells in layer $\mathrm{V}$ of MI remains unchanged (Wannier et al., 2005), indicating that there occurred no sizeable CS neurons loss. However, there remain space for debate, since after a spinal cord lesion in the macaque, only few apoptotic cells were detected inside the dorsolateral funiculus rostrally to the lesion (Crowe et al., 1997). This data suggests that the lesion induced at most a limited degeneration of the CS and RS axons, and hence that their cells of origin survive. In view of this data, additional evidence is required to establish the exact fate of axotomized RS neurons in the macaque.

\subsection{Cell size}

The measurement of the cross-sectional somatic areas of neurons in the RNm of both sides revealed that in all lesioned animals the contralesional RNm showed a significant reduction in cell size as compared to the ipsilesional side (Fig. 4). Conversely, in intact animals the cell size difference between the two RNm was not statistically significant. The median values of somatic cross-sectional areas of SMI-32-positive neurons obtained in the four intact monkeys ranged from 601 to $1268 \mu \mathrm{m}^{2}$, indicating a high inter-individual variability. These values are however in agreement with values previously reported (Burman et al., 2000a; Padel et al., 1981). In lesioned animals the ipsilesional RNm showed median values ranging between 526 and $1023 \mu \mathrm{m}^{2}$. These values indicated again a considerable individual variability and were comparable, as expected, to the ones observed in intact animals. In contrast, the contralesional RNm showed lower median values ranging from 413 to $787 \mu \mathrm{m}^{2}$. The box plot distribution and statistical analysis showed that this difference in somatic cross-sectional area between the RNm of the two sides was significant for all lesioned monkeys (Figs. 4A, B). In contrast, the percentage difference of median values of somatic cross sectional area 
between the two $\mathrm{RNm}$ on each side ranged from $1.1 \%$ to $-9.4 \%$ in intact animals and none was statistically significant. The relationship between the values of cross-sectional area difference and the extent of the lesion was not straightforward. For instance, the lowest percentage difference of somatic cross-sectional area $(-13.6 \%, \mathrm{Mk}-\mathrm{CH})$ was found in an animal with complete transection of the RS/CS tracts, whereas in this animal the cell number difference between the two RNm was relatively high $(-35.3 \%)$. In general, the poor correlation with parameters such as lesion extent and survival time is due to an individual variability, representing a major aspect of the impact of axotomy at cervical level. This variability is also reflected in the literature by the divergent results reported with respect to cell death and cell body shrinkage.

\subsection{Anti-Nogo-A antibody treatment}

Anti-Nogo-A antibody treatment applied at the level of the spinal cord lesion did influence neither the number nor crosssectional-somatic area of SMI positive neurons in the contralesional RNm. In other words, the treatment did not have a measurable impact on RS cell body survival or maintenance. Such a protective effect may have been expected as an indirect consequence of the increased number of synaptic boutons which is associated with the sprouting and/or regeneration which is commonly induced by the neutralization of Nogo-A. Indeed, new synapses could provide additional sources of neurotrophic substances and thus help neurons to respond to the damaging effects of axotomy. As no study has yet investigated whether the neutralization of Nogo-A promotes sprouting and/or regeneration of RS neurons in the nonhuman primate, the question remains as to whether the absence of effects reported here indicates that these neurons do not generate new synapses in response to the treatment. This view is however rather unlikely, because no effect on the number or volume of SMI-32 neurons was observed for axotomized CS neurons (Beaud et al., 2006). For these neurons, the mechanisms mentioned above should have then entered in action, as the neutralization of Nogo-A has been shown to promote CS axonal sprouting after cervical spinal cord lesion in rats (Bregman et al., 1995; Liebscher et al., 2005; Schwab, 2004), marmoset monkeys (Fouad et al., 2004) and macaque monkeys (Freund et al., 2006, 2007). Nevertheless, the issue of whether anti-Nogo-A antibody treatment enhances sprouting of the RS tract in non-human primates remains an open question that will require future attention.

\section{Experimental procedures}

All animals included in the present study belong to a long-term research project on spinal cord lesion from which post-lesion changes in the CS system were described earlier (Freund et al., 2006, 2007; Schmidlin et al., 2005, 2004; Wannier et al., 2005). To assess the number of RS neurons in this model, midbrain sections including the red nucleus were obtained from 15 adult (3-8 years old) macaque monkeys (Macaca mulatta or Macaca fascicularis). All experiments were conducted in accordance with the Guide for the care and Use of Laboratory animals (ISBN 0-309-05377-3; 1996) and approved by the local (Swiss) veterinary authority. Following an initial period of 2-3 months during which the animals were trained to perform several manual dexterity tasks until they reached a stable level of performance, 11 of these 15 monkeys were subjected to section of the cervical spinal cord. The lesion consisted of a unilateral transection performed at the C7/C8 border. The manual dexterity performances were assessed for several months post-lesion, until the animals reached a plateau reflecting a stable level of manual dexterity. The behavioural, electrophysiological and neuroanatomical tracing data related to the CS tract derived from these animals were described in previous reports (Freund et al., 2006, 2007; Schmidlin et al., 2005, 2004; Wannier et al., 2005). The present report is focussed on anatomical aspects dealing specifically with the issue of fate of RS neurons after unilateral cervical section. Therefore, only the methods relevant to this specific issue will be described in detail below. In addition, the anatomical data derived from the 11 lesioned monkeys were compared with data derived from 4 intact monkeys.

\subsection{Surgical procedures}

The surgical procedures for the unilateral spinal cord lesion at C7/C8 level have been described in detail in previous reports; (Freund et al., 2006, 2007; Schmidlin et al., 2004; Wannier et al., 2005). Briefly, the animal was anesthetized by intramuscular (i.m.) injection of ketamine (Ketalar®; Parke-Davis, $5 \mathrm{mg} / \mathrm{kg}$, i.m.). Before surgery, atropine was injected i.m. (0.05 mg/kg) to reduce bronchial secretions and the animal was treated with the analgesic Carprofen (Rymadil $囚, 4 \mathrm{mg} / \mathrm{kg}$, s.c.). To assure and monitor deep anesthesia, a catheter was placed in the femoral vein for continuous perfusion with a mixture of propofol $1 \%$ (Fresenius ${ }^{\circledR}$ ) and a $4 \%$ glucose solution (1 volume of Propofol and 2 volumes of glucose solution). The animal was placed in a ventral decubitus position, with his head kept in a flexed position ventrally to expose the posterior cervical region. Under sterile conditions, a complete C6 laminectomy and an upper C7 hemi-laminectomy were performed to expose the spinal cord. Next, the dura mater was incised longitudinally. To perform the unilateral section of the spinal cord at the C7/C8 border, the dorsal root entry zone, identified under the microscope, was taken as the most medial landmark. From this target, a surgical blade (no 11, Paragon $®$ ) was inserted $4 \mathrm{~mm}$ in depth perpendicularly to the spinal cord, and the section was prolonged laterally to completely transect the dorsolateral funiculus. The rostro-caudal levels were the dorsal rootlets entering respectively the 7th and the 8th cervical spinal segments. This region corresponds to the rostral zone of the spinal portion covered by the 6 th cervical lamina. The muscles and the skin were sutured and the animal recovered from anaesthesia in about half of an hour. After the spinal lesion, the animal was kept alone in a separate cage for a few days, to allow best conditions for recovery. Then, the usual housing in groups with other monkeys was restored. To assess the effect of a regenerative treatment, an osmotic pump (Alzet $囚$, 2ML2, flow: $5 \mu \mathrm{l} / \mathrm{h}$ ) delivering either a monoclonal mouse IgG or an antibody neutralizing Nogo-A was inserted subcutaneously between the shoulder blades and changed once after 2 weeks. In order to deliver the antibody in close proximity of the lesion, the free tip of a polyethylene tube attached to the pump was fixed under the dura few $\mathrm{mm}$ rostrally to the cervical lesion. 


\subsection{Anti-Nogo-A antibodies}

Two monoclonal antibodies (mAbs) against different sites of Nogo-A were employed: the mouse mAb $11 \mathrm{C} 7$ was raised against a 18 amino acid sequence of rat Nogo-A (aa623-640) close to the most inhibitory region of the Nogo-A protein (Oertle et al., 2003). The second antibody used, $\mathrm{mAb}$ hNogo-A recognized the NogoA specific region of the human Nogo-A sequence. Both antibodies identify primate Nogo-A monospecifically on Western blots (Freund et al., 2006, 2007; Oertle et al., 2003; Weinmann et al., 2006). The antibodies were purified as IgGs and concentrated to $3.7-10 \mathrm{mg} / \mathrm{ml}$ in PBS (Freund et al., 2007).

\subsection{Control antibodies}

Purified IgG of a mouse mAb directed against wheat auxin (AMS Biotechnology, Oxon/UK) was used as control antibody (concentration: $3.7-10 \mathrm{mg} / \mathrm{ml}$ ).

\subsection{Histology}

Monkeys were sacrificed at different time points (days) postlesion (Table 1). For sacrifice, the animal was first sedated with ketamine and subsequently deeply anaesthetized by an intraperitoneal injection of a lethal dose of pentobarbital $(90 \mathrm{mg} / \mathrm{kg})$. Monkeys were perfused transcardially with $0.4 \mathrm{l}$ of $0.9 \%$ saline, followed by $4 \mathrm{l}$ of fixative (4\% solution of paraformaldehyde in $0.1 \mathrm{M}$ phosphate buffer, $\mathrm{pH}=7.6)$. This fixative was followed by 3 solutions of sucrose of increasing concentration $(10 \%$ in fixative, $20 \%$ and $30 \%$ in phosphate buffer) to prepare the tissue for cryoprotection. For this purpose, after dissection the brain and the spinal cord were additionally stored in a 30\% sucrose solution for 1-2 days. Frozen sections of the brain comprising both sides of the midbrain at the level of the RN were cut in the coronal plane at a thickness of $50 \mu \mathrm{m}$. The sections were distributed into eight series. The lesion site was reconstructed from camera lucida drawings of individual paralongitudinal consecutive Nissl-stained sections of the cervical spinal cord. The drawings were then aligned to allow reconstruction of the location and extent of the lesion on a transverse view of the spinal cord (Fig. 1), as previously described (Schmidlin et al., 2004; Wannier et al., 2005). In one monkey (Mk-AT, Table 1) the size of the lesion could not be estimated due to poor quality of the spinal cord tissue after histological processing.

A series of brain sections was stained immunocytochemically with a monoclonal SMI-32 antibody (Sternberger Monoclonals, Covance Antibodies, USA). The epitope recognized by the SMI-32 antibody lies on non-phosphorylated regions of the neurofilament protein and is only expressed by particular categories of neurons (Campbell and Morrison, 1989; Tsang et al., 2000). Standard immunohistochemical procedures were used as previously described (Liu et al., 2002). Comparison of adjacent series of sections stained either for Nissl or with the SMI-32 antibody indicated that virtually all neurons in the RNm were labelled by this antibody (see Results). As the brain was cut into 8 series (see above), sections stained with the SMI-32 antibody and including entire rostro-caudal extent of the RNm were usually six to nine. For every animal, all sections were included in the analysis.
To evaluate the effect of the lesion on RS neurons, we analysed the series of coronal sections stained for SMI-32 through the midbrain and we identified the position and the extent of the RNm close to the roots of the oculomotor cranial nerve (Fig. 2A) (Paxinos et al., 2000). Well stained SMI-32 positive RNm cells were easily identifiable even using low magnification $(\times 40)$. In lesioned animals, RNm neurons on the contralesional side were smaller and somewhat more faintly stained than ipsilaterally, and therefore some of them may have escaped detection at low magnification. To circumvent the problem, the quantitative analysis was conducted at higher magnification $(\times 400)$ for better discrimination. The number of SMI-32 stained RNm cells and the projected surface of their cell body was obtained from digitized photomicrographs using appropriate software (Neurolucida®). The neurons included in this analysis were SMI-32 positive and had a visible nucleus (Fig. 2B). The possibility of sampling the RNm neurons as required by stereological methods appeared not applicable here as the number of neurons responding to the criteria listed above was relatively small. Instead, all RNm neurons filling the above criteria were counted on each individual section. In addition, our aim was not to establish the absolute total number of cells in the RNm but to compare the number and size of neurons in the RNm on each side. This method was shown to be reliable in the motor cortex for the CS neurons (Wannier et al., 2005). Furthermore, in six animals (data not shown) the cross-sectional area of the nucleus of all neurons included in the counting was calculated. The derived maximal value of the diameter ranged from 8.5 to $20.8 \mu \mathrm{m}$. These values were far below the section thickness of $50 \mu \mathrm{m}$. Thus, the possibility of introducing significant counting errors by including fractions of the cells is unlikely. Only the soma without the numerous dendritic ramifications was underlined to determine the cell body cross-sectional area. Because of the presence of large dendritic ramifications (Fig. 2B) the cell body contour was in some cases difficult to delineate. Therefore, we considered that, along these large processes, the soma ended at a distance of $20 \mu \mathrm{m}$ from the nucleus, thus corresponding to the same procedure as used for CS neurons (Wannier et al., 2005). For comparison, brain sections from four intact animals, which had been included in previous tracing studies (Liu et al., 2002), were used as control material for the SMI-32 analysis of RNm neurons. Counts of SMI-32 positive RNm neurons and measurements of their somatic cross-sectional area were performed for each monkey on both right and left brain side on coronal sections, separated by $400 \mu \mathrm{m}$ each. The rostrocaudal dimensions of the RNm thus analysed was consistent with the calculated dimensions of the RNm as derived from the atlas of the macaque brain (Paxinos et al., 2000). Each section comprised both the right and left side of the brain (except for Mk-AS). When cutting the midbrain, care was taken to position the bloc parallel to the coronal plane so that for each section the two RNm were at a similar level. As shown already for the cerebral cortex (Wannier et al., 2005), although the sections shrank to some degree, the shrinkage was very similar for the two brain sides on a given section. In other words, cell counts and somatic cross-sectional area measurements were performed on brain halves of comparable thickness for each section analyzed. Consequently, the quantitative comparisons regarding the number of RNm neurons and their somatic crosssectional area have been conducted on comparable volumes of 
tissue in RNm. Data were then analysed with the SPSS software for statistical evaluation of the significance of cell number difference and cross-sectional area difference between the RNm neurons on the two sides of midbrain. Statistical analysis on the cell number was conducted by comparing the number of cells in each histological section and on the RNm of each brain side. The data obtained were analysed by means of the Wilcoxon signedrank, 1-tailed test. In one monkey (Mk-AS) this analysis could not be performed as the two brain sides were processed separately and it was not possible to compare equivalent levels of the RNm for each side. The statistical analysis concerning the cross sectional somatic area was performed by using the nonparametric Mann and Whitney test (see Results).

\section{Acknowledgments}

The authors wish to thank the technical assistance of Christiane Marti, Georgette Fischer, Monika Bennefeld, Véronique Moret, Françoise Tinguely and Christine Roulin (histology and behavioural evaluations), Josef Corpataux, Bernard Morandi, Bernard Bapst and Laurent Bossy (animal house keeping), André Gaillard (mechanics), Bernard Aebischer (electronics), Laurent Monney (informatics). We thank Prof. Pierre Lavenex for helpful discussions.

\section{R E F E R E N C ES}

Beaud, M.-L., Wannier, T., Schmidlin, E., Freund, P., Bloch, J., Mir, A., Schwab, M.E., Rouiller, E.M., 2006. Anti-Nogo-A treatment enhanced sprouting of corticospinal axons but did not prevent cell body shrinkage in the motor cortex in adult monkeys subjected to unilateral cervical cord lesion. FENS Abstr. A217.1.

Belhaj-Saïf, A., Cheney, P.D., 2000. Plasticity in the distribution of the red nucleus output to forearm muscles after unilateral lesions of the pyramidal tract. J. Neurophysiol. 83, 3147-3153.

Belhaj-Saïf, A., Hill Karrer, J., Cheney, P.D., 1998. Distribution and characteristics of poststimulus effects in proximal and distal forelimb muscles from red nucleus in the monkey. J. Neurophysiol. 79, 1777-1789.

Benes, F.M., Lange, N., 2001. Two-dimensional versus three-dimensional cell counting: a practical perspective. TINS 24, 11-17.

Bodian, D., 1946. Spinal projections of brainstem in rhesus monkey, deduced from retrograde chromatolysis. Anat. Rec. 94, 512-513.

Bregman, B.S., Kunkel-Bagden, E., Schnell, L., Dai, H.N., Gao, D., Schwab, M.E., 1995. Recovery from spinal cord injury mediated by antibodies to neurite growth inhibitors. Nature 378, 439-440.

Burman, K., Darian-Smith, C., Darian-Smith, I., 2000a. Geometry of rubrospinal, rubroolivary, and local circuit neurons in the macaque red nucleus. J. Comp. Neurol. 423, 197-219.

Burman, K., Darian-Smith, C., Darian-Smith, I., 2000b. Macaque red nucleus: origins of spinal and olivary projections and terminations of cortical inputs. J. Comp. Neurol. 423, 179-196.

Campbell, M.J., Morrison, J.H., 1989. Monoclonal antibody to neurofilament protein (SMI-32) labels a subpopulation of pyramidal neurons in the human and monkey neocortex. J. Comp. Neurol. 282, 191-205.

Crowe, M.J., Bresnahan, J.C., Shuman, S.L., Masters, J.N., Beattie, M.S., 1997. Apoptosis and delayed degeneration after spinal cord injury in rats and monkey. Nat. Med. 3, 73-76.
Egan, D.A., Flumerfelt, B.A., Gwyn, D.G., 1977. Axon reaction in the red nucleus of the rat. Perikaryal volume changes and the time course of chromatolysis following cervical and thoracic lesions. Acta Neuropathol. (Berl.) 37, 13-19.

Fouad, K., Klusman, I., Schwab, M.E., 2004. Regenerating corticospinal fibers in the Marmoset (Callitrix jacchus) after spinal cord lesion and treatment with anti-Nogo-A antibody IN-1. Eur. J. Neurosci. 20, 2479-2482.

Freund, P., Schmidlin, E., Wannier, T., Bloch, J., Mir, A., Schwab, M.E., Rouiller, E.M., 2006. Anti-Nogo-A treatment enhances corticospinal tract sprouting and functional recovery after unilateral cervical lesion in adult primates. Nat. Med. 12, 790-792.

Freund, P., Wannier, T., Schmidlin, E., Bloch, J., Mir, A., Schwab, M.E., Rouiller, E.M., 2007. Anti-Nogo-A antibody treatment enhances sprouting of corticospinal (CS) axons rostral to an unilateral cervical spinal cord lesion in adult macaque monkey. J. Comp. Neurol. 502, 644-659.

Geuna, S., 2000. Appreciating the difference between design-based and model-based sampling strategies in quantitative morphology of the nervous system. J. Comp. Neurol. 427, 333-339.

Hains, B.C., Black, J.A., Waxman, S.G., 2003. Primary cortical motor neurons undergo apoptosis after axotomizing spinal cord injury. J. Comp. Neurol. 462, 328-341.

Holstege, G., Blok, B.F., Ralston, D.D., 1988. Anatomical evidence for red nucleus projections to motoneuronal cell groups in the spinal cord of the monkey. Neurosci. Lett. 95, 97-101.

Houle, J.D., Ye, J.H., 1999. Survival of chronically-injured neurons can be prolonged by treatment with neurotrophic factors. Neuroscience 94, 929-936.

Kwon, B.K., Liu, J., Messerer, C., Kobayashi, N.R., McGraw, J., Oschipok, L., Tetzlaff, W., 2002. Survival and regeneration of rubrospinal neurons 1 year after spinal cord injury. Proc. Natl. Acad. Sci. U. S. A. 99, 3246-3251.

Kwon, B.K., Liu, J., Oschipok, L., Teh, J., Liu, Z.W., Tetzlaff, W., 2004. Rubrospinal neurons fail to respond to brain-derived neurotrophic factor applied to the spinal cord injury site 2 months after cervical axotomy. Exp. Neurol. 189, 45-57.

Lavenex, P., Steele, M.A., Jacobs, L.F., 2000. The seasonal pattern of cell proliferation and neuron number in the dentate gyrus of wild adult eastern grey squirrels. Eur. J. Neurosci. 12, 643-648.

Lee, B.H., Lee, K.H., Kim, U.J., Yoon, D.H., Sohn, J.-H., Choi, S.S., Yi, I.-G., Park, Y.G., 2004. Injury in the spinal cord may produce cell death in the brain. Brain Res. 1020, 37-44.

Liebscher, T., Schnell, L., Schnell, D., Scholl, J., Schneider, R., Gullo, M., Fouad, K., Mir, A., Rausch, M., Kindler, D., Hamers, F.P., Schwab, M.E., 2005. Nogo-A antibody improves regeneration and locomotion of spinal cord-injured rats. Ann. Neurol. 58, 706-719.

Liu, Y., Kim, D., Himes, B.T., Chow, S., Schallert, T., Murray, M., Tessler, A., Fischer, I., 1999. Transplant of fibroblasts genetically modified to express BDNF promote regeneration of adult rat rubrospinal axons and recovery of forelimb function. J. Neurosci. 19, 4370-4387.

Liu, J., Morel, A., Wannier, T., Rouiller, E.M., 2002. Origins of callosal projections to the supplementary motor area (SMA): a direct comparison between pre-SMA and SMA-proper in Macaque monkeys. J. Comp. Neurol. 443, 71-85.

Mori, F., Himes, B.T., Kowada, M., Murray, M., Tessler, A., 1997. fetal spinal cord transplants rescue some axotomized rubrospinal neurons from retrograde cell death in adult rats. Exp. Neurol. $143,45-60$.

Novikova, L.N., Novikov, L.N., Kellerth, J.-O., 2000. Survival effects of BDNF and NT-3 on axotomized rubrospinal neurons depend on the temporal pattern of neurotrophin administration. Eur. J. Neurosci. 12, 776-780.

Oertle, T., Van der Haar, M.E., Bantlow, C., Robeva, A., Burfeind, P., Buss, A., Huber, A.B., Simonen, M., Schnell, L., Brosamle, C., Kaupmann, K., Vallon, R., Schwab, M.E., 2003. Nogo-A inhibits 
neurite outgrowth and cell spreading with three discrete regions. J. Neurosci. 23, 5393-5406.

Padel, Y., Angaut, P., Massion, J., Sedan, R., 1981. Comparative study of the posterior red nucleus in baboons and gibbons. J. Comp. Neurol. 202, 421-438.

Paxinos, G., Huang, X.F., Toga, A.W., 2000. The Rhesus Monkey Brain in Stereotaxic Coordinates. Academic Press, London.

Prendergast, J., Stelzner, D.J., 1976. Changes in the magnocellular portion of the red nucleus following thoracic hemisection in the neonatal and adult rat. J. Comp. Neurol. 166, 163-172.

Raineteau, O., Fouad, K., Bareyre, F.M., Schwab, M.E., 2002. Reorganization of descending motor tracts in the rat spinal cord. Eur. J. Neurosci. 16, 1761-1771.

Ralston, D.D., Milroy, A.M., 1989. Red nucleus of Macaca fascicularis: an electron microscopic study of its synaptic organization. J. Comp. Neurol. 284, 602-620.

Schmidlin, E., Wannier, T., Bloch, J., Rouiller, E.M., 2004.

Progressive plastic changes in the hand representation of the primary motor cortex parallel incomplete recovery from unilateral section of the corticospinal tract at cervical level in monkeys. Brain Res. 1017, 172-183.

Schmidlin, E., Wannier, T., Bloch, J., Belhaj-Saïf, A., Wyss, A.F., Rouiller, E.M., 2005. Reduction of the hand representation in the ipsilateral primary motor cortex following unilateral section of the corticospinal tract at cervical level in monkeys. BMC Neuroscience 6, 56.

Schwab, M.E., 2004. Nogo and axon regeneration. Curr. Opin. Neurobiol. 14, 118-124.

Tetzlaff, W., Alexander, S.W., Miller, F.D., Bisby, M.A., 1991. Response of facial and rubrospinal neurons to axotomy: changes in mRNA expression for cytoskeletal proteins and GAP43. J. Neurosci. 11, 2528-2544.

Tsang, Y.M., Chiong, F., Kuznetsov, D., Kasarskis, E., Geula, C., 2000. Motor neurons are rich in non-phosphorylated neurofilaments: cross-species comparison and alterations in ALS. Brain Res. 861, 45-58.

Wannier, T., Schmidlin, E., Bloch, J., Rouiller, E.M., 2005. A unilateral section of the corticospinal tract at cervical level in primate does not lead to measurable cell loss in motor cortex. J. Neurotrauma 22, 703-717.

Weinmann, O., Schnell, L., Ghosh, A., Montani, L., Wiessner, C., Wannier, T., Rouiller, E.M., Mir, A., Schwab, M.E., 2006. Intrathecally infused antibodies against Nogo-A penetrate the CNS and downregulate the endogenous neurite growth inhibitor Nogo-A. Mol. Cell. Neurosci. 32, 161-173.

Xu, X.M., Martin, G.F., 1990. The response of rubrospinal neurons to axotomy in the adult opossum, Didelphis virginiana. Exp. Neurol. 108, 46-54. 